\title{
A NEW APPROACH IN THE EVALUATION OF C-POSITIVE VARIANTS IN MAN
}

\author{
Jun-ichi Azumi, Yasuo Nakagome, and Ei Matsunaga \\ Department of Human Genetics, National Institute of Genetics, Mishima
}

\begin{abstract}
Summary The size of C-positive qh regions of chromosomes 1, 9 and 16 was determined using a Nikon-Vickers M85 microdensitometer. Results (area) were expressed based on how different they were from an average of each 1qh; $9 \mathrm{qh}$ or $16 \mathrm{qh}$ region in terms of standard deviations (SD). It was proposed that a variant within $\pm 1 \mathrm{SD}$ of an average be assigned to the intermediate class (class 3) in the Paris Conference system (Suppl. 1975), one within \pm 2 SD to either small or large class (class 2 or 4 ) and all others to either very small or very large (class 1 or 5). The present system compares favorably with any other methods so far tested as to the detection of a qh variant.
\end{abstract}

\section{INTRODUCTION}

In the Paris Conference (Suppl. 1975), the use of numerical expression, 1 through 5 , was recommended for the purpose of describing the size of a variant. However, no specific definitions were given for the individual classes (numerals). As to the qh regions of Nos. 1, 9 and 16, the use of the size relative to either a 21q (Müller et al., 1975) or a 16p (Patil and Lubs, 1977) was proposed. The ratios thus obtained were assigned more or less arbitrarily into 5 classes.

In the present study, area of qh regions was measured using a microdensitometer. A few different methods were compared for the purpose of expressing the area in a more or less standardized form as well as for assigning it into one of 5 classes. The former was necessary to cancel possible effects of chromosome contraction and other technical variables. As to the latter, 3 methods including those of Müller et al. (1975), Patil and Lubs (1977) and a new system were compared.

\section{MATERIALS AND METHODS}

Chromosome preparations were obtained from 6 normal unrelated individuals by the standard leukocyte-culture technique. Slides were treated by the CBG (socalled BSG) technique (Sumner, 1972) after they were aged for 7 to 10 days.

Measurements of the area of chromosomes were carried out with a Nikon-

Received March 30, 1979 
Table 1. Methods of numerical expression for the size of $\mathrm{qh}$ segments.

\begin{tabular}{cccc}
\hline Class $^{a}$ & $\mathrm{~A}^{\mathrm{b}}$ & $\mathrm{B}$ & $\mathrm{C}$ \\
\hline 1 & $\leqq 0.25 \times 21 \mathrm{q}$ & $\leqq 0.5 \times 16 \mathrm{p}$ & $\leqq-2 \mathrm{SD}$ \\
2 & $\leqq 0.5 \times 21 \mathrm{q}$ & $\leqq 1.0 \times 16 \mathrm{p}$ & $>-2 \mathrm{SD}$ \\
3 & $\leqq 1.0 \times 21 \mathrm{q}$ & $\leqq 1.5 \times 16 \mathrm{p}$ & $+\mathrm{SD}>>-\mathrm{SD}$ \\
4 & $\leqq 1.5 \times 21 \mathrm{q}$ & $\leqq 2.0 \times 16 \mathrm{p}$ & $<+2 \mathrm{SD}$ \\
5 & $>1.5 \times 21 \mathrm{q}$ & $>2.0 \times 16 \mathrm{p}$ & $\geqq+2 \mathrm{SD}$ \\
\hline
\end{tabular}

a) Numerical expression of size variants proposed in the Paris Conference (Suppl., 1975). 1, very small; 2 , small; 3 , intermediate; 4 , large; 5 , very large.

b) A, Müller et al. (1975); B, Patil and Lubs (1977); C, present method.

Vickers M85 scanning microdensitometer. The monochromator was set at a wave length of $540 \mathrm{~nm}$ which corresponded to the maximum absorption of CBG treated chromosomes. The diameter of the flying spot was $0.2 \mu \mathrm{m}$. At least 5 well spread metaphases were measured in each case. Measurements of the area of a given chromosome, or a segment of it were carried out as follows:

(1) An adjustable rectangular mask was fixed in a position so as to contain only a given chromosome.

(2) Density of background was measured at 4 points around the chromosome. The average value was taken as a background level.

(3) Density was measured at 4 different spots within C-negative segments and 2 within a $\mathrm{C}$-positive segment of the chromosome, then average in each group was obtained.

(4) Therefore, 3 different levels of density were available for each chromosome. Two intermediate points between them were taken as an upper and a lower thresholds.

(5) The area above the upper threshold was taken as that of a C-positive (qh) segment and that above the lower threshold represented area of the chromosome. The area of a euchromatic (C-negative) segment was obtained after subtracting the former from the latter.

(6) The area of a complete chromosome set was measured using the lower threshold. A large and round mask was used to cover a whole metaphase spread. Background level was measured at 4 points around the metaphase.

(7) Results were converted into $\mu \mathrm{m}^{2}$ when necessary.

The size of a C-positive qh segment was expressed relative to that of either a long arm of chromosome 21 (21q) or a short arm of chromosome 16 (16p). Results were also expressed relative to the area of a given chromosome or euchromatic segment of it. The area of the entire chromosome set was also related. For each of the 5 groups of data, an average and a standard deviation were calculated.

To convert the results in the numerical ( 1 through 5 ) system as proposed in the Paris Conference (Suppl., 1975), three different methods, A, B and C (Table 1), were applied and results were compared. In the former two, a qh segment was ranked 
based on its size relative to that of a standard, a 21q in the A method and a $16 \mathrm{p}$ in the B. In the third, each qh segment was ranked based on the difference from an average and was expressed in standard deviations.

Table 2. Size of qh segments in chromosome 1.

\begin{tabular}{ccccccc}
\hline Individuals & & 1qh/21q & 1qh/16p & 1qh/1-qh & 1qh/chr.1 & 1qh/all chr. $(\times 100)$ \\
\hline 1 & a a) & $1.06^{\mathrm{b})}$ & 1.50 & 0.21 & 0.18 & 0.84 \\
& $\mathrm{~b}$ & 0.97 & 1.38 & 0.19 & 0.17 & 0.80 \\
2 & $\mathrm{a}$ & 1.09 & 1.55 & 0.21 & 0.18 & 0.80 \\
& $\mathrm{~b}$ & 1.02 & 1.43 & 0.19 & 0.15 & 0.69 \\
& $\mathrm{a}$ & 1.02 & 1.53 & 0.22 & 0.17 & 0.87 \\
& $\mathrm{~b}$ & 0.94 & 1.42 & 0.20 & 0.17 & 0.81 \\
& $\mathrm{a}$ & 1.13 & 1.64 & 0.25 & 0.19 & 0.94 \\
& $\mathrm{~b}$ & 1.06 & 1.56 & 0.22 & 0.18 & 0.88 \\
5 & $\mathrm{a}$ & 1.15 & 1.51 & 0.26 & 0.19 & 0.89 \\
& $\mathrm{~b}$ & 1.06 & 1.37 & 0.22 & 0.17 & 0.81 \\
6 & $\mathrm{a}$ & 1.20 & 1.69 & 0.25 & 0.20 & 0.94 \\
& $\mathrm{~b}$ & 1.10 & 1.42 & 0.21 & 0.18 & 0.80 \\
\hline Average & & 1.07 & 1.50 & 0.22 & 0.18 & 0.84 \\
SD & & 0.07 & 0.10 & 0.02 & 0.01 & 0.06 \\
\hline
\end{tabular}

a) One of the homologous pair with larger variant was arbitrarily marked as " $a$ ". and the other as "b."

b) Area of C-positive 1qh segment relative to the area of $21 \mathrm{q}, 16 \mathrm{p}$, euchromatic segment of 1 (1-qh), 1 or all 46 chromosomes.

Table 3. Size of qh segments in chromosomes 9 and 16.

\begin{tabular}{|c|c|c|c|c|c|c|c|}
\hline Individuals & & $9 q^{h} / 21 q^{a)}$ & $9 q h / 16 p$ & $9 \mathrm{qh} / 9-\mathrm{qh}$ & $16 q h / 21 q$ & $16 q h / 16 p$ & $16 \mathrm{qh} / 16-\mathrm{qh}$ \\
\hline \multirow[t]{2}{*}{1} & $a^{b 2}$ & 0.79 & 1.08 & 0.27 & 0.48 & 0.66 & 0.31 \\
\hline & $\mathrm{b}$ & 0.68 & 0.95 & 0.25 & 0.41 & 0.56 & 0.26 \\
\hline \multirow[t]{2}{*}{2} & $\mathrm{a}$ & 0.79 & 1.12 & 0.30 & 0.54 & 0.77 & 0.34 \\
\hline & $b$ & 0.75 & 1.06 & 0.27 & 0.41 & 0.58 & 0.30 \\
\hline \multirow[t]{2}{*}{3} & a & 0.72 & 1.04 & 0.30 & 0.47 & 0.70 & 0.36 \\
\hline & $b$ & 0.66 & 0.98 & 0.29 & 0.44 & 0.65 & 0.33 \\
\hline \multirow[t]{2}{*}{4} & $\mathrm{a}$ & 0.91 & 1.35 & 0.36 & 0.48 & 0.70 & 0.38 \\
\hline & $b$ & 0.73 & 1.07 & 0.31 & 0.36 & 0.56 & 0.34 \\
\hline \multirow[t]{2}{*}{5} & $\mathrm{a}$ & 0.96 & 1.27 & 0.35 & 0.47 & 0.62 & 0.32 \\
\hline & b & 0.75 & 0.99 & 0.29 & 0.35 & 0.47 & 0.22 \\
\hline \multirow[t]{2}{*}{6} & $a$ & 0.79 & 1.01 & 0.30 & 0.60 & 0.76 & 0.38 \\
\hline & b & 0.68 & 0.88 & 0.27 & 0.51 & 0.65 & 0.34 \\
\hline Average & & 0.76 & 1.07 & 0.29 & 0.46 & 0.64 & 0.32 \\
\hline SD & & 0.09 & 0.13 & 0.32 & 0.07 & 0.08 & 0.04 \\
\hline
\end{tabular}

a) $9 \mathrm{qh} / \mathrm{chr} .9,9 \mathrm{qh} / \mathrm{all} \mathrm{chr} ., 16 \mathrm{qh} / 16$ and $16 \mathrm{qh} / \mathrm{all} \mathrm{chr}$. were also calculated but they were omitted from the table. Most information they contained were, in fact, represented by the items included in the table.

b) See Table 2 . 
Table 4. Numerical expression of qh segments in chromosome 1.

\begin{tabular}{|c|c|c|c|c|c|c|c|c|}
\hline \multirow{2}{*}{ Individuals } & & \multicolumn{2}{|c|}{$1 \mathrm{qh} / 21 \mathrm{q}$} & \multicolumn{2}{|c|}{$1 \mathrm{qh} / 16 \mathrm{p}$} & \multirow{2}{*}{$\frac{1 \mathrm{qh} / 1-\mathrm{qh}}{\mathrm{C}}$} & \multirow{2}{*}{$\frac{1 \mathrm{qh} / \mathrm{chr} .1}{\mathrm{C}}$} & \multirow{2}{*}{$\frac{1 \mathrm{qh} / \mathrm{all} \mathrm{chr} .}{\mathrm{C}}$} \\
\hline & & $\left.A^{a}\right)$ & Ca) & $\left.\mathrm{B}^{2}\right)$ & $\mathrm{C}$ & & & \\
\hline \multirow[t]{2}{*}{1} & $\left.a^{b}\right)$ & 4 & 3 & 3 & 3 & 3 & 3 & 3 \\
\hline & $b$ & 3 & 2 & 3 & 2 & 2 & 2 & 3 \\
\hline \multirow[t]{2}{*}{2} & $\mathrm{a}$ & 4 & 3 & 4 & 3 & 3 & 3 & 3 \\
\hline & $b$ & 4 & 3 & 3 & 3 & 2 & 3 & 2 \\
\hline \multirow[t]{2}{*}{3} & a & 4 & 3 & 4 & 3 & 3 & 3 & 3 \\
\hline & $\mathrm{b}$ & 3 & 2 & 3 & 3 & 2 & 3 & 3 \\
\hline \multirow[t]{2}{*}{4} & $\mathrm{a}$ & 4 & 3 & 4 & 4 & 4 & 4 & 4 \\
\hline & $\mathrm{b}$ & 4 & 3 & 4 & 3 & 3 & 3 & 3 \\
\hline \multirow[t]{2}{*}{5} & $\mathrm{a}$ & 4 & 4 & 4 & 3 & 4 & 3 & 3 \\
\hline & $\mathrm{b}$ & 4 & 3 & 3 & 2 & 3 & 2 & 3 \\
\hline \multirow[t]{2}{*}{6} & $\mathrm{a}$ & 4 & 4 & 4 & 4 & 4 & 4 & 4 \\
\hline & $b$ & 4 & 3 & 3 & 3 & 3 & 3 & 3 \\
\hline Average & & 3.8 & 3.0 & 3.5 & 3.0 & 3.0 & 3.0 & 3.1 \\
\hline $\begin{array}{l}\text { No. of } \\
\text { variants } \\
\text { detected }\end{array}$ & & $2^{c j}$ & 4 & -d) & 4 & 6 & 4 & 3 \\
\hline
\end{tabular}

a) See Table 1. As to the $C$, see also text.

b) See Table 2 .

c) In criteria A and B, any qh segments belonging to different classes from the most popular one were taken as variants. By definition, class 3 represents the most popular one in the criterion $C$.

d' See text.

Table 5. Numerical expression of qh segments in chromosomes 9 and 16.a

\begin{tabular}{|c|c|c|c|c|c|c|c|c|c|c|c|}
\hline \multirow{2}{*}{ Individuals } & & \multicolumn{2}{|c|}{$9 \mathrm{qh} / 21 \mathrm{q}$} & \multicolumn{2}{|c|}{$9 q h / 16 p$} & \multirow{2}{*}{$\frac{9 \mathrm{qh} / 9-\mathrm{qh}}{\mathrm{C}}$} & \multicolumn{2}{|c|}{$16 q h / 21 q$} & \multicolumn{2}{|c|}{$16 \mathrm{qh} / 16 \mathrm{p}$} & \multirow{2}{*}{$\frac{16 q h / 16-q h}{C}$} \\
\hline & & A & $\mathrm{C}$ & $B$ & $\mathrm{C}$ & & $\mathrm{A}$ & $\mathrm{C}$ & B & $\mathrm{C}$ & \\
\hline \multirow[t]{2}{*}{1} & a & 3 & 3 & 3 & 3 & 3 & 2 & 3 & 2 & 3 & 3 \\
\hline & $b$ & 3 & 3 & 2 & 3 & 2 & 2 & 3 & 2 & 3 & 2 \\
\hline \multirow[t]{2}{*}{2} & a & 3 & 3 & 3 & 3 & 3 & 3 & 4 & 2 & 4 & 3 \\
\hline & $\mathrm{b}$ & 3 & 3 & 3 & 3 & 3 & 2 & 3 & 2 & 3 & 3 \\
\hline \multirow[t]{2}{*}{3} & a & 3 & 3 & 3 & 3 & 3 & 2 & 3 & 2 & 3 & 3 \\
\hline & b & 3 & 2 & 2 & 3 & 3 & 2 & 3 & 2 & 3 & 3 \\
\hline \multirow[t]{2}{*}{4} & $\mathrm{a}$ & 3 & 4 & 3 & 5 & 5 & 2 & 3 & 2 & 3 & 4 \\
\hline & b & 3 & 3 & 3 & 3 & 3 & 2 & 2 & 2 & 3 & 3 \\
\hline \multirow[t]{2}{*}{5} & $\mathrm{a}$ & 3 & 5 & 3 & 4 & 4 & 2 & 3 & 2 & 3 & 3 \\
\hline & b & 3 & 3 & 2 & 2 & 3 & 2 & 2 & 1 & 2 & 1 \\
\hline \multirow[t]{2}{*}{6} & $\mathrm{a}$ & 3 & 3 & 3 & 3 & 3 & 3 & 5 & 2 & 4 & 4 \\
\hline & $b$ & 3 & 3 & 2 & 2 & 3 & 3 & 3 & 2 & 3 & 3 \\
\hline Average & & 3.0 & 3.2 & 2.7 & 3.1 & 3.2 & 2.3 & 3.1 & 1.9 & 3.1 & 2.9 \\
\hline $\begin{array}{l}\text { No. of } \\
\text { variants } \\
\text { detected }\end{array}$ & & 0 & 3 & 4 & 4 & 3 & 3 & 4 & 1 & 3 & 4 \\
\hline
\end{tabular}

a) For legends see Table 4. 


\section{RESULTS}

The mean area of C-positive $1 \mathrm{qh}, 9 \mathrm{qh}$ and $16 \mathrm{qh}$ segments were $1.98 \pm 0.31$ $\left(\mu \mathrm{m}^{2} \pm \mathrm{SD}\right), 1.39 \pm 0.28$ and $0.83 \pm 0.17$, respectively.

As to 1qh segments, all of the data obtained were presented in Table 2. In Table 3, data on $9 \mathrm{qh}$ and $16 \mathrm{qh}$ were presented together. Some of the items were not included in the table as they were judged to bring no additional information. It appeared that all $16 \mathrm{qh}$ segments were smaller than both $21 \mathrm{q}$ and $16 \mathrm{p}$, while almost all lqh segments were larger than them. When results were expressed in the numerical system, the same trend was clearly observed (Tables 4 and 5). The mean score for 1qh segments were 3.8 and 3.5 by A and B methods, while those for 16qh were 2.3 and 1.9 respectively. By the $B$ methods, 6 of twelve 1qh segments were in the class 3 and the rest in the class 4 . Thus, it was meaningless to rank one of them as a variant class. As to $9 \mathrm{qh}$ segments, the method A did not appear practical.

To rank an average sized segment as class 3 and to detect variants efficiently in each of $1 \mathrm{qh}, 9 \mathrm{qh}$ and $16 \mathrm{qh}$ segment, a different approach was required. A newmethod (method $\mathrm{C}$ in the Table 1) ranks a qh segment into one of 5 classes based on how close to (or remote from) an average of each $1 \mathrm{qh}, 9 \mathrm{qh}$ or $16 \mathrm{qh}$ segment. A segment within $\pm 1 \mathrm{SD}$ of the average is ranked as intermediate in size (class 3 ). A segment rated class 5 is very large ( $\geqq+2 \mathrm{SD}$ ), that in the class 1 is very small $(\leqq-2 \mathrm{SD})$. One in the class 2 or 4 is either small or large. Results were presented in Tables 4 and 5.

\section{DISCUSSION}

Numbers of variants detected in $1 \mathrm{qh}, 9 \mathrm{qh}$ and $16 \mathrm{qh}$ by the A method were 2, 0 and 3 and those by the B were 0,4 and 1 respectively (Tables 4 and 5). When the data from the same source (Tables 2 and 3 ) were analysed by the present $(C)$ method, corresponding numbers were 4,3 and 4 for the former (qh/21q) and 4, 4 and 3 for the latter $(\mathrm{qh} / 16 \mathrm{p})$. The present method detected twice as much variants than either the A or the B method using the same data with the latter two. As to 9qh segments, the method $\mathrm{B}$ detected as much variants as the $\mathrm{C}$ (Table 5). However, the close examination of both results as well as original data presented in the Table 3 revealed that in the $\mathrm{B}$ method, some of the qh segments with the size very close to the average, e.g., $1 \mathrm{~b}, 3 \mathrm{~b}$ and $5 \mathrm{~b}$, were ranked as variants. They were so to say "pseudo-variants." On the other hand, two largest members, i.e., $4 \mathrm{a}$ and 5a, were included in the class 3 . Therefore, the class 3 does not represent a group of variants "intermediate" in size, nor class 2 those "small" in size. This obviously is contradictory to the system suggested in the Paris Conference (see Table 1). The same holds true in the method A. On the other hand, variants were ranked based on how close (or remote) they were from an average in the present method. By defi- 
nition, no "pseudo-variants" can arise. In a previous paper, we described a method in which the size of a $\mathrm{qh}$ region was evaluated based on the difference from the average of a given qh segment (Nakagome et al., 1977). However, results were expressed as, e.g., between $\pm 25 \%$ of an average. In the present paper, the difference was expressed in a statistically defined form. Thus the results are open for further processing and for comparison with those obtained in the other laboratory.

The present method was applied to every data included in Tables 2 and 3 and proved itself to be very useful in all of them. However, examinations of both Tables 4 and 5 revealed that the number of detected variants was the highest when the size of a $\mathrm{qh}$ segment was expressed relative to that of a euchromatic segment of the same chromosome and then ranked by the present method. The reason may be that possible effects of chromosome contraction or elongation were reduced when segments of the same chromosome was used as a reference standard.

Acknowledgments This study was supported in part by grants from the Ministry of Health and Welfare and from the Ministry of Education, Science and Culture of Japan (No. 357650 to Y.N.).

\section{REFERENCES}

Müller, H., Klinger, H. P., and Glasser, M. 1975. Chromosome polymorphism in a human newborn population. II. Potentials of polymorphic chromosome variants for characterizing the idiogram of an individual. Cytogenet. Cell Genet, 15: 239-255.

Nakagome, Y., Oka, S., and Matsunaga, E. 1977. LBA technique in the detection of chromosome variants. II. Chromosomes except for those with $\mathrm{Q}$ variants. Human Genet. 38: 307-314.

Paris Conference, Supplement. 1975. Standardization in Human Cytogenetics. Birth Defects, Orig. Art. Ser., Vol. 11, No. 9, Natl. Fdtn., New York.

Patil, S. R. and Lubs, H. A. 1977. Classification of qh regions in human chromosomes 1, 9 and 16 by C-banding. Human Genet. 38: 35-38.

Sumner, A. T. 1972. A simple technique for demonstrating centromeric heterochromatin. Exp. Cell Res. 75: 304-306. 